\title{
Plant responses to plant growth-promoting rhizobacteria
}

\author{
L. C. van Loon
}

Received: 4 December 2006/Accepted: 3 May 2007/Published online: 5 June 2007

(C) KNPV 2007

\begin{abstract}
Non-pathogenic soilborne microorganisms can promote plant growth, as well as suppress diseases. Plant growth promotion is taken to result from improved nutrient acquisition or hormonal stimulation. Disease suppression can occur through microbial antagonism or induction of resistance in the plant. Several rhizobacterial strains have been shown to act as plant growth-promoting bacteria through both stimulation of growth and induced systemic resistance (ISR), but it is not clear in how far both mechanisms are connected. Induced resistance is manifested as a reduction of the number of diseased plants or in disease severity upon subsequent infection by a pathogen. Such reduced disease susceptibility can be local or systemic, result from developmental or environmental factors and depend on multiple mechanisms. The spectrum of diseases to which PGPRelicited ISR confers enhanced resistance overlaps partly with that of pathogen-induced systemic acquired resistance (SAR). Both ISR and SAR represent a state of enhanced basal resistance of the plant that depends on the signalling compounds jasmonic acid and salicylic acid, respectively, and pathogens are differentially sensitive to the resistances activated by each of
\end{abstract}

L. C. van Loon $(\bowtie)$

Department of Biology, Section Phytopathology, Institute of Environmental Biology, Faculty of Science, Utrecht University, P.O. Box 800.84, 3508 TB Utrecht,

The Netherlands

e-mail: 1.c.vanloon@uu.nl these signalling pathways. Root-colonizing Pseudomonas bacteria have been shown to alter plant gene expression in roots and leaves to different extents, indicative of recognition of one or more bacterial determinants by specific plant receptors. Conversely, plants can alter root exudation and secrete compounds that interfere with quorum sensing (QS) regulation in the bacteria. Such two-way signalling resembles the interaction of root-nodulating Rhizobia with legumes and between mycorrhizal fungi and roots of the majority of plant species. Although ISR-eliciting rhizobacteria can induce typical early defence-related responses in cell suspensions, in plants they do not necessarily activate defence-related gene expression. Instead, they appear to act through priming of effective resistance mechanisms, as reflected by earlier and stronger defence reactions once infection occurs.

Keywords Arabidopsis - Disease suppression · Induced systemic resistance $\cdot$ Plant growth promotion - Signal transduction .

Systemic acquired resistance

\section{Plant growth promotion by rhizobacteria}

Plant roots offer a niche for the proliferation of soil bacteria that thrive on root exudates and lysates. Population densities of bacteria in the rhizosphere may be up to 1,00-fold higher than in bulk soil and up 
to $15 \%$ of the root surface may be covered by microcolonies of a variety of bacterial strains. While these bacteria utilize the nutrients that are released from the host for their growth, they also secrete metabolites into the rhizosphere. Several of these metabolites can act as signalling compounds that are perceived by neighbouring cells within the same micro-colony, by cells of other bacteria that are present in the rhizosphere, or by root cells of the host plant (Van Loon and Bakker 2003; Bais et al. 2004; Gray and Smith 2005; Kiely et al. 2006).

The best-studied example of signal exchange is the Rhizobium-legume symbiosis, in which the plant releases flavonoid compounds that act as signals for the bacterium to secrete Nod factors. Nod factors are perceived by plant root hairs and function in a hormone-like fashion to induce root nodules in which the Rhizobium bacterium can fix atmospheric nitrogen. The bacterium grows at the expense of carbohydrates from the host, but provides fixed nitrogen for amino acid biosynthesis in return (Brencic and Winans 2005; Gray and Smith 2005). This symbiosis is a prime example of an intimate relationship between a soil bacterium and its host plant, and illustrates the concept behind the term 'plant growthpromoting rhizobacteria' (PGPR): in nitrogen-poor environments the Rhizobium bacterium promotes legume plant growth by providing a limiting nutrient.

Growth promotion by soil microorganisms is far from uncommon (Glick et al. 1999; Ryu et al. 2005) and can be considered part of a continuum in which interactions between plants and microorganisms range from deleterious (pathogens) to beneficial (PGPR). In the Netherlands, already 75 years ago observations were made by an assistant of Professor Johanna Westerdijk at the Phytopathological Laboratory 'Willie Commelin Scholten' in Baarn, about recovery from damping-off in turfgrass. The person, by the name of Van Luijk, identified several pathogenic Pythium species that were responsible for the disease, but he also observed that grass seeds germinated to a higher percentage in non-sterile than in sterilized soil (Van Luijk 1938). This was the first demonstration in the Netherlands that soil microorganisms can promote plant growth. The reason for this stimulatory effect of the biological agent present in the raw soil became clear only later. It turned out that non-pathogenic Pythium spp. were also present, took over and counteracted the actions of the pathogenic Pythium spp. and other deleterious soil microorganisms through microbial antagonism. These observations were the beginning of a research programme on antagonism between microorganisms that has been continuing to this day at Utrecht University.

The stimulation of seed germination and the recovery from damping-off of the turfgrass that were caused by the non-pathogenic Pythium spp. were apparent as a promotion of growth relative to appropriate control plants. However, in reality they were the result of disease suppression. Many bacteria in soil have similar properties (Compant et al. 2005; Haas and Défago 2005), but in a number of cases rhizobacteria can enhance plant growth in the absence of potentially pathogenic microorganisms, as has been shown in e.g. gnotobiotic systems (Van Loon and Bakker 2003). Over the years, several mechanisms of rhizobacterial growth promotion have been documented (Table 1). The ability to fix atmospheric nitrogen is present in various bacterial species that are either free-living in the soil, or associated with plant roots by growing endophytically (Dobbelaere et al. 2003). Poorly soluble inorganic nutrients that are rate-limiting for growth can be made available through the solubilizing action of bacterial siderophores or the secretion of organic acids (Vessey 2003). The high population densities of bacteria in the rhizosphere stimulate nutrient delivery and uptake by plant roots.

Other mechanisms of growth promotion involve modulation of plant regulatory mechanisms through the production of hormones or other compounds that influence plant development (Frankenberger and Arshad 1995). Many bacterial species are capable of producing auxin and/or ethylene, and synthesis of gibberellins and cytokinins has also been documented. Introduction of the rhizobacterial strain Pseudomonas fluorescens WCS417 in autoclaved soil promoted growth of Arabidopsis accession Col-0 by 33\% (Pieterse and Van Loon 1999). A comparable growth promotion was seen when Arabidopsis seedlings were grown under gnotobiotic conditions on vertically oriented agar plates containing halfstrength Hoagland nutrient medium. Compared to sterile grown control seedlings, WCS417-treated seedlings showed enhanced shoot and root development, enhanced greening and lateral root formation (S. van der Ent unpublished observation). Whether 
Table 1 Mechanisms of plant growth promotion by rhizobacteria

Nitrogen fixation

Ion uptake

Iron, zinc, other essential micronutrients

Phosphate

Production of plant hormones

Auxins, gibberellins, cytokinins, ethylene

Modulation of plant development

ACC deaminase

'Elicitors'

WCS417 produces plant hormones is not known, but promotion of lateral root formation is a typical auxin effect (Tanimoto 2005). Obviously, enhanced lateral root formation increases the capacity to take up nutrients. For Azospirillum brasilense it has been shown that auxin is responsible for its growthpromoting action in wheat and pearl millet, as bacterial mutants that had lost $70 \%$ of their capacity to produce indole-acetic acid had lost their plant growth-promoting activity (Barbieri and Galli 1993).

Gibberellins and cytokinins both stimulate shoot development. Their effects on root growth are less well documented. Ethylene is usually considered an inhibitor of plant growth, but at low levels can actually promote growth in several plant species, including Arabidopsis (Pierik et al. 2006). At moderate levels it inhibits both root and shoot elongation, and at high levels it enhances senescence and organ abscission (Abeles et al. 1992). The direct precursor of ethylene in the plant biosynthetic pathway, 1-aminocyclopropane-1-carboxylic acid (ACC) is exuded from plant roots together with other amino acids. Rhizobacteria that possess the enzyme ACC deaminase can degrade ACC and utilize it as a carbon source. Under such conditions, re-uptake by the roots is prevented and the level of ACC in the roots is reduced. As a consequence, ethylene production by the roots is lowered, relieving inhibition of root growth. Thus, ACC deaminase-containing rhizobacteria can increase root growth by lowering endogenous ACC levels (Glick 2005). However, bacteria lacking ACC deaminase have also been shown to increase plant growth and such observations cannot be explained by known mechanisms. It is presumed that under such conditions bacterial cells possess certain surface components or secrete compounds that act as 'elicitors' of plant growth. Plant roots must be able to perceive and recognize such elicitors in ways similar to the recognition of elicitors from plant pathogens. In fact, plant pathogens might interfere with the action of PGPR by being perceived by similar receptors.

\section{Plant-mediated disease suppression by rhizobacteria}

When plants are growing naturally in soils, one cannot distinguish whether an apparent growth promotion is caused by bacterially stimulated plant growth or through suppression of deleterious soil microorganisms. Non-pathogenic rhizobacteria can antagonize pathogens through competition for nutrients, production of antibiotics and secretion of lytic enzymes (Handelsman and Stabb 1996; Van Loon and Bakker 2003). Such activities are particularly important in the rhizosphere where pathogenic fungi are attracted to plant roots. However, rhizobacteria can reduce the activity of pathogenic microorganisms not only through microbial antagonism, but also by activating the plant to better defend itself. This phenomenon, termed 'induced systemic resistance' (ISR) was first described by Van Peer et al. (1991) in carnation that was systemically protected against Fusarium oxysporum f.sp. dianthi upon treatment with strain WCS417, and by Wei et al. (1991) in cucumber, where six out of 94 rhizobacterial strains protected the leaves against anthracnose caused by Colletotrichum orbiculare. Protection as a result of microbial antagonism was excluded because the inducing rhizobacteria and the challenging pathogens were inoculated at, and remained confined to, spatially separated parts on the same plants. Hence, the protective effect was plant-mediated.

ISR confers on the plant an enhanced defensive capacity (Van Loon et al. 1998; Van Loon and Bakker 2005). Upon infection with a challenging pathogen this enhanced defensive capacity is manifested as a reduction in the rate of disease development, resulting in fewer diseased plants or in lesser disease severity. The induced resistance is also evident locally and sometimes does not extend systemically (Van Loon 2000). When only local, it is difficult to prove, because the inducing bacterium and the challenging pathogen are not separated from 
each other and direct antagonism is difficult to rule out. Only when specific eliciting components of the inducer are active in stimulating resistance in the plant but inactive in antagonizing the pathogen in vitro on different types of media, can locally induced resistance be inferred. Induction of resistance by live organisms always requires proof that the organisms cannot contact each other, a condition that can be met when an inducing rhizobacterium remains confined to the roots and the challenging pathogen colonizes only the leaves. Under such situations the inducing bacterium must trigger the roots to locally produce a signal that moves to the leaves to activate the enhanced defensive capacity systemically. The nature of this mobile signal has so far remained elusive.

Since its discovery, rhizobacteria-mediated ISR has been documented in at least 15 plant species (Van Loon and Bakker 2006). Its induction has been shown to share several characteristics (Table 2A), but its expression can involve different physiological mechanisms (Table 2B). ISR can be induced by various non-pathogenic microorganisms and by some types of stress that activate the same response in the plant. In contrast to $R$-gene-mediated resistance, it is not specific but active against all types of pathogens, as well as against several nematodes and insects. Once induced, plants may remain protected for a considerable part of their lifetime, indicating that when the state of ISR has been triggered in the plant, it is rather stable (Van Loon et al. 1998).

Upon challenge inoculation, ISR is expressed as a result of the altered physiological state of the plant. Expression may take different forms, depending on the activity of the inducing rhizobacterium and the nature of the interaction between the pathogen and the plant (Chester 1933). In fact, 'induced resistance' is an operational term to denote a condition in which a plant becomes less diseased compared to a control plant that was not induced. There are many ways in which developmental and environmental factors can influence plant-pathogen interactions. Damping-off due to infection by Pythium, Fusarium or Rhizoctonia is often confined to the seedling stage. Any condition that results in more rapid plant growth will shorten the vulnerable stage and be apparent as enhanced resistance. Rhizobacteria acting through growth promotion could protect plants through this mechanism. A similar type of ISR could occur in potato where accelerated development leads to enhanced adult plant resistance against late blight caused by Phytophthora infestans (Visker et al. 2003).

Some reports on ISR have indicated reduced symptom expression in the absence of a reduction in pathogen proliferation. This tolerance of the plant to the pathogen must have a physiological basis. Examples are the reduced damage of Pythium ultimum-infected cucumbers and lesser extent of soft rot of potato infected by Erwinia carotovora pv. carotovora upon prior treatment of the plants with ACC deaminase-containing rhizobacterial strains. By lowering the level of stress ethylene in the plant due to pathogenic attack, ACC deaminase acted synergistically with other mechanisms of biocontrol in reducing symptom development without having an effect on the population density of the pathogen (Wang et al. 2000).

Reduced disease can also be the outcome of alterations in the microbial populations in the rhizosphere as a result of altered host physiology. Numbers of resistance-inducing bacteria may be changed, or their expression of resistance-inducing traits may be altered (Mark et al. 2005). Plants commonly react to root colonization by rhizobacteria by increasing the release of exudates, and quantity and composition of root exudates vary with plant developmental stage (Phillips et al. 2004). Thus, plant growth promotion could alter root exudation. Moreover, rhizobacteria that act as minor pathogens or are perceived by the plant as a potential threat, are likely to change the rate and composition of exudates, and to increase the release of lysates.

The population densities and the diversity of the root microflora may affect the number and activity of resistance-inducing rhizobacteria. Quorum sensing (QS) within and between bacterial populations is a major regulatory mechanism in bacteria to adjust their metabolism to crowded conditions or other changes in the biotic and abiotic environment (Whitehead et al. 2001). Interference with bacterial QS by host plants has been documented. Plants can produce and secrete various compounds that mimic QS signals of bacteria and, thereby, alter bacterial activities in the rhizosphere (Bauer and Mathesius 2004). The ecological diversity and its consequences for metabolic activity of rhizosphere bacteria are only poorly known at present and deserve further investigation. 
Table 2 The nature of systemically induced resistance in plants

(A) Characteristics of induced systemic resistance

The defensive capacity of the plant is enhanced through microbial stimulation or similar stresses

The enhanced defensive capacity is expressed systemically throughout the plant

Induced systemic resistance is active against fungi, bacteria, viruses and, sometimes, nematodes and insects

Once induced, systemic resistance is maintained for prolonged periods

(B) Mechanisms of induced systemic resistance

Developmental, escape: linked to growth promotion

Physiological, tolerance: reduced symptom expression

Environmental: associated with microbial antagonism in the rhizosphere; altered plant-insect interactions

Biochemical, resistance: induction of cell wall reinforcement,

Induction of phytoalexins

Induction of pathogenesis-related proteins

'Priming' of defence responses (resistance)

Rhizobacteria can also alter plant secondary metabolism, resulting in changed plant-insect relationships. Root colonization of cucumber by four different PGPR reduced the level of cucurbitacin, which acts as a feeding stimulant to cucumber beetles (Zehnder et al. 1997). Similar effects on insects that can transmit viruses, might reduce virus diseases through induced resistance against the insect vector rather than against the virus itself.

Finally, non-pathogenic rhizobacteria may activate inducible defence mechanisms in the plant in a similar way to pathogenic microorganisms. Such mechanisms can include reinforcement of plant cell walls, production of anti-microbial phytoalexins, synthesis of pathogenesis-related proteins (PRs) (Hammond-Kosack and Jones 1996), as well as an enhanced capacity to express these defence responses upon challenge inoculation with a pathogen, a mechanism known as 'priming' (Conrath et al. 2006). Activation of defence reactions suggests that even a beneficial rhizobacterium may be perceived by the plant as a potential threat, and that such perception involves production of resistance-eliciting compounds that act mechanistically similar to elicitors produced by plant pathogenic fungi and bacteria. Both nitrogen-fixing Rhizobia in legume root nodules and vesicular-arbuscular (VA) mycorrhizal fungi in roots have been shown to activate plant host defences when the symbiotic interaction becomes unproductive (Parniske et al. 1991; Hause and Fester 2005). Plants possess sensitive mechanisms to perceive both fungi and bacteria through conserved components that are specific to their kingdoms and act as general elicitors. These are commonly referred to as 'pathogen-associated molecular patterns' (PAMPs) (Nürnberger and Lipke 2005). During compatible plant-pathogen interactions and effective symbioses, the microorganisms actively suppress defensive activities in the host (Da Cunha et al. 2006). The relationship between root-colonizing, resistance-inducing PGPR and their hosts seems substantially less intimate than with either Rhizobia or mycorrhizal fungi, but the idea that PGPR may at the same time trigger and suppress defence reactions in the host, deserves consideration.

\section{Expression of systemically induced resistance in the plant}

Besides biochemical techniques, such as enzyme activity measurements and protein analysis, the development of molecular-biological techniques has allowed the reaction of plants to rhizobacteria to be determined at the transcriptional level by analyzing differential gene expression by a variety of techniques. Changes in a number of host plants in reaction to several resistance-inducing strains have been documented (Table 3). Many authors report increases in stress-related enzyme activities such as phenylalanine ammonia-lyase, peroxidase, polyphenoloxidase, B-1,3-glucanase and chitinase, as well as induction of specific PRs in leaves of plants of which the roots were colonized by resistance-inducing PGPR (reviewed in Van Loon and Bakker 2005, 
Table 3 Changes in gene expression in bacterized plants

\begin{tabular}{|c|c|c|c|c|c|}
\hline \multirow[t]{2}{*}{ Bacterial strain } & \multirow[t]{2}{*}{ Host plant } & \multicolumn{2}{|c|}{ Systemically in leaves } & \multicolumn{2}{|c|}{ Locally in roots } \\
\hline & & Up & Down & Up & Down \\
\hline Various & Various & PRs & & & \\
\hline Paenibacillus polymyxa $\mathrm{B} 2$ & Arabidopsis & 10 & & & \\
\hline Pseudomonas thivervalensis MLG45 & Arabidopsis & 42 & 21 & 0 & 9 \\
\hline Pseudomonas fluorescens WCS417 & Arabidopsis & 0 & 0 & 39 & 63 \\
\hline Pseudomonas chlororaphis $\mathrm{O} 6$ & Cucumber & 0 & & & \\
\hline Pseudomonas fluorescens FPT9601-T5 & Arabidopsis & 95 & 105 & & \\
\hline \multirow[t]{2}{*}{ Bacillus subtilis M4 } & Cucumber & $3.7 \%$ & $2.5 \%$ & & \\
\hline & Tomato & $6.2 \%$ & $4.7 \%$ & & \\
\hline Pseudomonas fluorescens C7R12 & M. trunculata & & & 58 & \\
\hline
\end{tabular}

For references and details, see main text

2006). Park and Kloepper (2000) used Arabidopsis transformed with a $P R-1$ promoter- $\beta$-glucuronidase $(G U S)$ reporter construct and monitored GUS expression in response to nine rhizobacterial strains in plants growing either in vitro on agar plates or in vivo in soil. Almost all strains induced the $P R-1$ promoter to varying levels, and expression was correlated roughly with known resistance-inducing properties of these strains. Thus, in these Arabidopsis plants, resistance-inducing PGPR induced defence reactions commonly associated with pathogen infection.

Similar results were obtained by Timmusk and Wagner (1999), who concluded that the resistanceinducing strain Paenibacillus polymyxa B2 induced mild biotic stress. These authors used gnotobioticallyraised plants on a nutrient medium, and by applying RNA differential display and real-time PCR, found six and an additional four genes, respectively, to be upregulated in response to the PGPR, including $P R-1$ and the drought-responsive gene ERD15. The significance of the latter observation is difficult to assess. However, it is known that water relations of sterilegrown plants are different from those in the natural environment and the bacteria obviously affected the water potential of the roots.

Using cDNA micro-arrays representing approximately 14,300 genes, Cartieux et al. (2003) monitored gene expression in both leaves and roots of axenic Arabidopsis plants infected by resistanceinducing Pseudomonas thivervalensis strain MLG45. Plants colonized by this rhizobacterium showed decreased photosynthetic rates and reduced growth, indicating that $P$. thivervalensis acted as a minor pathogen rather than a PGPR. This conclusion was supported by the changes in gene expression observed. In the leaves, genes associated with photosynthesis and chloroplast functioning, as well as several unknowns, were downregulated, whereas genes implicated in stress, wounding, oxidative burst, or disease resistance were upregulated. However, no typical $P R$ genes were activated. Surprisingly few changes were noted at the site of bacterial colonization, i.e. the roots. Colonized root systems showed an approximately $50 \%$ reduction in primary root length and an increase in lateral root formation, but levels of only nine transcripts were reduced and none was elevated compared to control roots.

These results contrast with those of Verhagen et al. (2004), who determined changes in gene expression of Arabidopsis plants grown on rock wool in the presence of strain WCS417, using an Arabidopsis GeneChip Microarray representing about 8,000 genes. Locally in the roots, substantial changes were found in the expression of 97 genes, including ones involved in cell rescue and defence, metabolism, transcription, cellular communication and signal transduction, particularly those involved in ethylene signalling. No consistent changes were found in the leaves, indicating that the onset of ISR as a result of root colonization by WCS417 is not associated with detectable changes in gene expression in the leaves. Comparable results were obtained by Kim et al. (2004), who, using subtractive hybridisation, did not detect any changes in leaves of cucumber plants grown in sterilized soilless growing medium from seeds coated with Pseudomonas chlororaphis $\mathrm{O6}$, a strain that was effective in inducing 
systemic resistance against target leaf spot caused by Corynespora cassiicola.

Like WCS417, Pseudomonas fluorescens FPT9601-T5 was found to trigger ISR in Arabidopsis against Pseudomonas syringae pv. tomato. Using an Affymetrix GeneChip probe array containing approximately 22,800 genes, Wang et al. (2005) detected 95 and 105 genes that were up- and downregulated, respectively, in leaves of soil-grown plants that had been root-dipped in a suspension of the bacteria. Changes in root gene expression were not analysed. Strain FPT9601-T5 was originally identified as an endophytic PGPR in tomato. It also promoted the growth of Arabidopsis plants, even though it suppressed growth in early stages of root colonization. Among the upregulated genes were ones involved in metabolism, signal transduction and stress responses, including a number of $P R$-like genes. Noteworthy, putative auxin-regulated genes, suggested to be related to the observed growth promotion, and nodulin-like genes were upregulated, whereas some ethylene-responsive genes were downregulated, indicating that some parts of signalling pathways related to plant defence seemed to be suppressed. These observations point to a similarity in the relationship of endophytic PGPR and Rhizobia with their host plants, as Rhizobia reduce plant ethylene levels during nodule formation (Ma et al. 2003). In its interaction with Arabidopsis, FPT9601-T5 may possess intermediate characteristics between WCS417 and $P$. thivervalensis MLG45. However, PRs were not induced in the leaves of plants of which the roots had been colonized by either of the latter two strains (Wang et al. 2005). These data indicate that Arabidopsis reacts quite differently to different PGPR, even though all these bacterial strains are able to trigger ISR in this species. In every case, the number of genes with altered expression was modest, perhaps because of stringent selection criteria employed.

Using cDNA-AFLP, Ongena et al. (2005) estimated that in leaves of cucumber and tomato plants $3.7 \%$ and $6.2 \%$ of all genes were upregulated and $6.2 \%$ and $4.7 \%$ were downregulated, respectively, in response to root colonization by Bacillus subtilis strain M4. As crop plants are estimated to possess even more genes than the model plant Arabidopsis (about 25,000) (Bevan and Walsh 2006), those percentages correspond to a total of a few 1,000 genes, substantially more than the numbers described in the other studies. However, the nature of the genes with altered expression levels was not investigated. Analysis of the reaction of tomato to the ISR-eliciting strain Serratia liquefaciens MG1, using a macroarray containing cDNA probes of 70 defence-related and signalling genes, revealed enhanced expression of 12 genes. Seven of those coded for PRs, whereas the others were involved in oxidative stress, ethylene signalling, or metabolism (Shuhegger et al. 2006).

In roots of the legume species Medicago trunculata, Sanchez et al. (2005) found 58 genes to be upregulated in response to colonization by the growth-promoting strain Pseudomonas fluorescens C7R12, a number in line with that found by Verhagen et al. (2004) in Arabidopsis roots colonized by strain WCS417. Out of 10 of the C7R12-induced genes, 9 were not upregulated in the $M$. trunculata dmi3 mutant, which is impaired in the signal transduction pathway of the Nod factor from Sinorhizobium meliloti as well as in mycorrhization by the fungus Glomus mosseae. Of those 10 genes, S. meliloti activated only one and inhibited four others in wildtype $M$. trunculata, whereas $G$. mosseae activated all 10. These data indicate that $M$. trunculata shares common molecular pathways in the perception of $P$. fluorescens and G. mosseae, and to a minor extent $S$. meliloti. Thus, root-colonizing Pseudomonas spp. appear to activate signalling pathways in the plant in common with symbiotic mycorrhizal fungi and nitrogen-fixing Rhizobia.

\section{Signalling pathways of systemically induced resistance}

The activation of certain $P R$ genes in some, though not all, plant-PGPR interactions suggests that the systemic resistance that is induced by the rhizobacterium is similar to pathogen-induced systemic acquired resistance (SAR) (e.g. Wang et al. 2005). SAR signalling in the plant is dependent on salicylic acid (SA) and the regulatory protein NPR1, as evidenced by the loss of SAR in transgenic NahG plants that are unable to accumulate SA, and in the nprl mutant (Sticher et al. 1997). The enhanced defensive capacity characteristic of SAR is always associated with the accumulation of PRs. Notably, PR-1 is commonly taken as a marker that SAR has been induced (Kessmann et al. 1994). In Arabidopsis, 
SA-dependent SAR is typically associated with the activation of three $P R$ genes: $P R-1,-2$ and -5 . The pathogen $P$. syringae $\mathrm{pv}$. tomato induces SAR, together with a strong activation of these genes, which results in a reduction in both the proliferation of, and symptoms of bacterial speck induced by the same pathogen when induced plants are challengeinoculated. Plants that were root-inoculated with nonpathogenic WCS417 did not show PR-gene expression before challenge inoculation, even though they did express the capacity to reduce proliferation of the pathogen and symptoms of bacterial speck disease to similar extents upon challenge inoculation (Pieterse et al. 1996).

Whereas ISR in the leaves was not associated with detectable changes in gene expression, upon challenge inoculation with $P$. syringae pv. tomato 82 genes showed an augmented expression pattern in ISR-expressing leaves. Of these, 16 genes were upregulated and 14 downregulated in induced, but not in non-induced plants (Verhagen et al. 2004), indicating that the expression of these genes was altered only in plants expressing ISR. Thus, not only were several genes primed to respond faster or more strongly upon pathogen attack, but also a substantial number were expressed in an ISR-specific way. Of the primed genes, $70 \%$ were dependent on jasmonate (JA) and/or ethylene (ET) signalling, 13\% were both JA- and/or ET- and SA-dependent, and $17 \%$ were regulated differently. None of the genes were SAdependent. These results confirm earlier findings that WCS417-elicited ISR in Arabidopsis is not associated with activation of the SA signalling pathway but requires responsiveness to JA and ET (Pieterse et al. 1998; Van Wees et al. 1999).

In accordance with the differences in signalling pathways, SAR and ISR were found to differ in their effectiveness against different types of attackers. On Arabidopsis, pathogens that are sensitive to both SAand JA/ET-dependent defences, such as the oomycete Hyaloperonospora parasitica, the fungus Fusarium oxysporum, and the bacteria P. syringae and Xanthomonas campestris, were restricted by both SAR and ISR. In contrast, only ISR was active against the necrotrophic fungi Alternaria brassicicola and Botrytis cinerea, whereas only SAR was effective against Turnip crinkle virus (Ton et al. 2002). As to insect attackers, neither SAR nor ISR reduced feeding damage by larvae of the cabbage white butterfly
Pieris rapae, whereas both were effective against the beet army worm Spodoptera exigua (V. R. van Oosten personal communication). Hence, the spectrum of effectiveness of SAR and ISR is only partly overlapping, reflecting the different signalling pathways involved.

\section{Induction of systemically induced resistance in the plant}

By using the available SA-non-accumulating NahG transformants in Arabidopsis, tobacco and tomato, and various plant mutants impaired in JA or ET signalling, the dependence of systemically induced resistance elicited by various PGPR in these three plant species on SA, JA and/or ET has been determined. ISR elicited by almost all strains was found to be SA-independent, also by strains such as $P$. fluorescens CHA0 and Serratia marcescens 90-66, that can themselves produce $\mathrm{SA}$ as an additional siderophore (reviewed in Van Loon and Bakker 2005). Only the systemic resistance induced by Pseudomonas aeruginosa strain 7NSK2 was SA-dependent (De Meyer et al. 1999). For tomato it was established that it is not the SA which is produced by this strain that triggers ISR, but synthesis of the SA-containing siderophore pyochelin and the antibiotic pyocyanin. In combination, pyochelin and pyocyanin induce the formation of oxygen free radicals in the roots, which triggers SA production in the plant and subsequent activation of an SA-dependent enhanced resistance (Audenaert et al. 2002). Bacillus spp. activate some of the same signalling pathways as Pseudomonas spp., but can also trigger additional pathways that act independently of NPR1 (Kloepper et al. 2004).

PGPR that elicit ISR in one plant species, may not do so in another, again indicating specificity in the interaction between rhizobacteria and plants. Whereas generally rhizobacteria are not dainty in colonizing roots of different plant species, the perception by the plant of bacterial determinants that trigger ISR appears to be quite specific (Bakker et al. 2003; Meziane et al. 2005; Van Loon and Bakker 2005). Apparently, one or more bacterial components need to be recognized by specific plant receptors. Of three strains, Pseudomonas putida WCS358 and $P$. fluorescens WCS374 and WCS417, none is active in eliciting ISR in all out of six plant species 
(Table 4), even though levels of root colonization are similar. Remarkably, in Arabidopsis strain WCS374 was differentially active in eliciting ISR against different pathogens depending on bioassay conditions (M. Djavaheri personal communication), suggesting that the type and effectiveness of the systemic resistance that is induced by this rhizobacterium is variable.

Failure to elicit ISR on certain hosts may be due to the absence of production of inducing components in the rhizosphere, or to an inability of the particular plant species to perceive such compounds. Usually, a minimum population density of $10^{5}$ colony-forming units per gram of root is required for ISR to be triggered (Raaijmakers et al. 1995), suggesting that QS signals may be necessary for the production of the eliciting compounds by the bacteria. Certain host plants have been shown to interfere with bacterial QS in the rhizosphere (Bauer and Mathesius 2004), and this could impede production of elicitors of ISR. Otherwise, root exudates may not provide critical compounds for elicitor production by the bacterium. Lack of perception has been shown to be responsible for the absence of defence-related reactions in Arabidopsis accession Ws-0 in reaction to the bacterial PAMP flagellin (Gómez-Gómez and Boller 2002; Zipfel et al. 2004). Flagellin contains a widely conserved 22-amino acid peptide that is recognized by a LRR-receptor kinase in the plasma membrane of Arabidopsis accessions such as the commonly used Col-0. The receptor is lacking in accession Ws-0. However, Ws-0 is also impaired in ethylene sensitivity and, therefore, cannot express ISR (Ton et al. 2001).

By bacterial mutant and complementation analysis several bacterial determinants of ISR elicitation in

Table 4 Differential induction of systemic resistance by Pseudomonas spp. strains

\begin{tabular}{llll}
\hline Host plant & WCS358 & WCS374 & WCS417 \\
\hline Arabidopsis & + & $-/+$ & + \\
Bean & + & nd & + \\
Carnation & - & nd & + \\
Radish & - & + & + \\
Rice & - & + & - \\
Tomato & + & nd & + \\
\hline
\end{tabular}

+, Induced; -, Not induced; nd, Not determined
Table 5 Bacterial determinants of induced systemic resistance in different plant species

Lipopolysaccharides: lipid A; O-antigenic sidechain

Siderophores: pseudobactins; pyochelin; (SA)

Flagella

Antibiotics: pyocyanin, 2,4-diacetylphloroglucinol

$\mathrm{N}$-acylhomoserine lactones

Volatile compounds: 2,3-butanediol

Adapted from Van Loon and Bakker (2005)

different plant species have been identified (Table 5). Arabidopsis appears particularly prone to induction, as it develops ISR after treatment with cell wall preparations consisting mainly of lipopolysaccharide (LPS), pseudobactin siderophores, flagella (Meziane et al. 2005), the antibiotic 2,4-diacetylphloroglucinol (Iavicoli et al. 2003; Weller et al. 2004), and the volatile metabolite 2,3-butanediol (Ryu et al. 2004). Siderophores and antibiotics are produced by the bacteria to compete for iron and to inhibit other strains in the rhizosphere, respectively, and thus have dual functions in microbial antagonism on the one hand, and elicitation of ISR on the other. The siderophore pyochelin and the antibiotic pyocyanin are both required for the induction of systemic resistance in tomato by $P$. aeruginosa 7NSK2 (Audenaert et al. 2002). QS $N$-acylhomoserine lactones were recently shown to act as inducers of systemic resistance in tomato against Alternaria alternata (Shuhegger et al. 2006). The compound 2,3-butanediol is produced by Bacillus spp. and not only elicits ISR, but is also involved in promoting growth in Arabidopsis (Ryu et al. 2003). How 2,3butanediol exerts its action and how far both mechanisms are connected, is presently unclear.

The LPS of the biocontrol bacterium Burkholderia cepacia has been shown to induce an oxidative burst, as well as a rapid influx of $\mathrm{Ca}^{2+}$ and extracellular alkalinization of the medium of tobacco suspension cells (Gerber et al. 2004), all three typical early events in the elicitation of defence responses in plantpathogen interactions (Nürnberger and Scheel 2001; Garcia-Brugger et al. 2006). Indeed, in whole plants of tobacco (Coventry and Dubery 2001) and Arabidopsis (Zeidler et al. 2004), the LPS induced substantial amounts of PRs and activation of $P R$ genes, respectively, suggesting that the LPS of 
B. cepacia acted by activating the SA signalling pathway.

Since ISR elicited by almost all rhizobacterial strains in Arabidopsis, tobacco and tomato is SAindependent and not associated with significant activation of $P R$ genes, it is still an open question in how far their inducing determinants activate early defence reactions. The variety of eliciting compounds precludes recognition by common receptors. Hence, perception by different receptors may trigger different early signalling events, which may or may not quickly converge into a common response. Even for the LPS, both lipid A (Erbs and Newman 2003) and the O-antigenic side-chain (Leeman et al. 1995) have been shown to be each capable of inducing resistance, but of a different type. Thus, preparations of LPS may activate more than a single pathway, contributing to their effectivenesss in a wide array of plant species. The specificity in the reactions of different plant species to individual strains (Table 4) indicates that the reactions of plants to resistance-inducing PGPR must be the outcome of a dynamic interplay between the production and the perception of ISReliciting signals. Whereas some PGPR activate defence-related gene expression, others appear to act solely through priming of effective resistance mechanisms, as reflected by earlier and stronger defence reactions once infection occurs.

\section{References}

Abeles, F. B., Morgan, P. W., \& Salveit, M. E. Jr. (1992). Ethylene in plant biology (2nd ed.). San Diego: Academic Press.

Audenaert, K., Pattery, T., Cornelis, P., \& Höfte, M. (2002). Induction of systemic resistance to Botrytis cinerea in tomato by Pseudomonas aeruginosa 7NSK2: Role of salicylic acid, pyochelin, and pyocyanin. Molecular Plant-Microbe Interactions, 15, 1147-1156.

Bais, H. P., Park, S.-W., Weir, T. L., Callaway, R. M., \& Vivanco, J. M. (2004) How plants communicate using the underground information superhighway. Trends in Plant Science, 9, 26-32.

Bakker, P. A. H. M., Ran, L. X., Pieterse, C. M. J., \& Van Loon, L. C. (2003). Understanding the involvement of rhizobacteria-mediated induction of systemic resistance in biocontrol of plant diseases. Canadian Journal of Plant Pathology, 25, 5-9.

Barbieri, P., \& Galli, E. (1993). Effect on wheat root development of inoculation with an Azospirillum brasilense mutant with altered indole-3-acetic acid production. Research in Microbiology, 144, 69-75.
Bauer, W. D., \& Mathesius, U. (2004). Plant responses to bacterial quorum sensing signals. Current Opinion in Plant Biology, 7, 429-433.

Bevan, M., \& Walsh, S. (2006). The Arabidopsis genome: A foundation for plant research. Genome Research, 15, 1632-1642.

Brencic, A., \& Winans, S. C. (2005). Detection of and response to signals involved in host-microbe interactions by plantassociated bacteria. Microbiology and Molecular Biology Reviews, 69, 155-194.

Cartieaux, F., Thibaud, M. C., Zimmerli, L., Lessard, P., Sarrobert, C., David, P., Gerbaud, A., Robaglia, C., Somerville, S., \& Nussaume, L. (2003). Transcriptome analysis of Arabidopsis colonized by a plant-growth promoting rhizobacterium reveals a general effect on disease resistance. The Plant Journal, 36, 177-188.

Chester, K. S. (1933). The problem of acquired physiological immunity in plants (continued). The Quarterly Review of Biology, 8, 275-324.

Compant, S., Duffy, B., Nowak, J., Clément, C., \& Barka, E. A. (2005). Use of plant growth-promoting bacteria for biocontrol of plant diseases: Principles, mechanisms of action, and future prospects. Applied and Environmental Microbiology, 71, 4951-4959.

Conrath, U., Beckers, G. J. M., Flors, V., García-Agustín, P., Jakab, G., Mauch, F., Newman M.-A., Pieterse, C. M. J., Poinssot, B., Pozo, M. J., Pugin, A., Schaffrath, U., Ton, J., Wendehenne, D., Zimmerli, L., \& Mauch-Mani, B. (2006). Priming: Getting ready for battle. Molecular Plant-Microbe Interactions, 19, 1062-1071.

Coventry, H. S., \& Dubery, I. A. (2001). Lipopolysaccharides from Burkholderia cepacia contribute to an enhanced defensive capacity and the induction of pathogenesis-related proteins in Nicotianae tabacum. Physiological and Molecular Plant Pathology, 58, 149-158.

Da Cunha, L., McFall, A. J., \& Mackey, D. (2006). Innate immunity in plants: A continuum of layered defenses. Microbes and Infection, 8, 1372-1381.

De Meyer, G., Audenaert, K., \& Höfte, M. (1999). Pseudomonas aeruginosa 7NSK2-induced systemic resistance in tobacco depends on in planta salicylic acid accumulation but is not associated with PR1a expression. European Journal of Plant Pathology, 105, 513-517.

Dobbelaere, S., Vanderleyden, J., \& Okon, Y. (2003). Plant growth-promoting effects of diazotrophs in the rhizosphere. Critical Reviews in Plant Sciences, 22, 107-149.

Erbs, G., \& Newman, M. A. (2003). The role of lipopolysaccharides in induction of plant defence responses. Molecular Plant Pathology, 4, 421-425.

Frankenberger, W. T., \& Arshad, M. (1995). Phytohormones in soils-microbial production and function. New York: Marcel Dekker.

Garcia-Brugger, A., Lamotte, O., Vandelle, E., Bourque, S., Lecourieux, D., Poinssot, B., Wendehenne, D., \& Pugin, A. (2006). Early signaling events induced by elicitors of plant defenses. Molecular Plant-Microbe Interactions, 19, 711-724.

Gerber, I. B., Zeidler, D., Durner, J., \& Dubery, I. A. (2004). Early perception responses of Nicotiana tabacum cells in response to lipopolysaccharides from Bulkholderia cepacia. Planta, 218, 647-657. 
Glick, B. R. (2005). Modulation of plant ethylene levels by the bacterial enzyme ACC deaminase. FEMS Microbiology Letters, 251, 1-7.

Glick, B. R., Patten, C. L., Holguin, G., \& Penrose, D. M. (1999). Biochemical and genetic mechanisms used by plant growth promoting bacteria. London: Imperial College Press.

Gómez-Gómez, L., \& Boller, T. (2002). Flagellin perception: A paradigm for innate immunity. Trends in Plant Science, 7, 251-256.

Gray, E. J., \& Smith, D. L. (2005). Intracellular and extracellular PGPR: Commonalities and distinctions in the plantbacterium signaling process. Soil Biology \& Biochemistry, 37, 395-412.

Haas, D., \& Défago, G. (2005). Biological control of soil-borne pathogens by fluorescent pseudomonads. Nature Reviews Microbiology, 3, 307-319.

Hammond-Kosack, K. E., \& Jones, J. D. G. (1996). Resistance gene-dependent plant defense responses. The Plant Cell, 8, 1773-1791.

Handelsman, J., \& Stabb, E. V. (1996). Biocontrol of soilborne plant pathogens. The Plant Cell, 8, 1855-1869.

Hause, B., \& Fester, T. (2005). Molecular and cell biology of arbuscular mycorrhizal symbiosis. Planta, 221, 184-196.

Iavicoli, A., Boutet, E., Buchala, A., \& Métraux, J.-P. (2003). Induced systemic resistance in Arabidopsis thaliana in response to root inoculation with Pseudomonas fluorescens CHA0. Molecular Plant-Microbe Interactions, 16, 851-858.

Kessmann, H., Staub, T., Ligon, J., Oostendorp, M., \& Ryals, J. (1994). Activation of systemic acquired disease resistance in plants. European Journal of Plant Pathology, 100, 359-369.

Kiely, P. D., Haynes, J. M., Higgins, C. H., Franks, A., Mark, G. L., Morrissey, J. P., \& O'Gara, F. (2006). Exploiting new systems-based strategies to elucidate plant-bacterial interactions in the rhizosphere. Microbial Ecology, 51, 257-266.

Kim, M. S., Kim, Y. C., \& Cho, B. H. (2004). Gene expression analysis in cucumber leaves primed by root colonization with Pseudomonas chlororaphis O6 upon challengeinoculation with Corynespora cassiicola. Plant Biology, 6, 105-108.

Kloepper, J. W., Ryu, C.-M., \& Zhang, S. A. (2004). Induced systemic resistance and promotion of growth by Bacillus spp. Phytopathology, 94, 1259-1266.

Leeman, M., Van Pelt, J. A., Den Ouden, F. M., Heinsbroek, M., Bakker, P. A. H. M., \& Schippers, B. (1995). Induction of systemic resistance against fusarium wilt of radish by lipopolysaccharides of Pseudomonas fluorescens. Phytopathology, 85, 1021-1027.

Ma, W. B., Guinel, F. C., \& Glick, B. R. (2003). Rhizobium leguminosarum biovar viciae 1-aminocyclopropane-1carboxylate deaminase promotes nodulation of pea plants. Applied and Environmental Microbiology, 69, 4396-4402.

Mark, G. L., Dow, J. M., Kiely, P. D., Higgins, H., Haynes, J., Baysse, C., Abbas, A., Foley, T., Franks, A., Morrissey, J., \& O'Gara, F. (2005). Transcriptome profiling of bacterial responses to root exudates identifies genes involved in microbe-plant interactions. Proceedings of the National Academy of Sciences of the United States of America, 102, 17454-17459.
Meziane, H., Van der Sluis, I., Van Loon, L. C., Höfte, M., \& Bakker, P. A. H. M. (2005). Determinants of Pseudomonas putida WCS358 involved in inducing systemic resistance in plants. Molecular Plant Pathology, 6, 177-185.

Nürnberger, T., \& Lipka, V. (2005). Non-host resistance in plants: New insights into an old phenomenon. Molecular Plant Pathology, 6, 335-345.

Nürnberger, T., \& Scheel, D. (2001). Signal transmission in the plant immune response. Trends in Plant Science, 6, 372-379.

Ongena, M., Duby, F., Jourdan, E., Beaudry, T., Jadin, V., Dommes, J., \& Thonart, P. (2005). Bacillus subtilis M4 decreases plant susceptibility towards fungal pathogens by increasing host resistance associated with differential gene expression. Applied Microbiology and Biotechnology, 67, 692-698.

Park, K. S., \& Kloepper, J. W. (2000). Activation of PR-1a promoter by rhizobacteria which induce systemic resistance in tobacco against Pseudomonas syringae pv. tabaci. Biological Control, 18, 2-9.

Parniske, M., Fischer, H.-M., Hennecke, H., \& Werner, D. (1991). Accumulation of the phytoalexin glyceollin I in soybean nodules infected by a Bradyrhizobium japonicum nifA mutant. Zeitschrift für Naturforschung, 46, 318-320.

Phillips, D. A., Fox, T. C., King, M. D., Bhuvaneswari, T. V., \& Teuber, L. R. (2004). Microbial products trigger amino acid exudation from plant roots. Plant Physiology, 136, 2887-2894.

Pierik, R., Tholen, D., Poorter, H., Visser, E. J. W., \& Voesenek, L. A. C. J. (2006). The Janus face of ethylene: Growth inhibition and stimulation. Trends in Plant Science, 11, 176-183.

Pieterse, C. M. J., \& Van Loon, L. C. (1999). Salicylic acidindependent plant defence pathways. Trends in Plant Science, 4, 52-58.

Pieterse, C. M. J., Van Wees, S. C. M., Hoffland, E., Van Pelt, J. A., \& Van Loon, L. C. (1996). Systemic resistance in Arabidopsis induced by biocontrol bacteria is independent of salicylic acid accumulation and pathogenesis-related gene expression. The Plant Cell, 8, 1225-1237.

Pieterse, C. M. J., Van Wees, S. C. M., Van Pelt, J. A., Knoester, M., Laan, R., Gerrits, H., Weisbeek, P. J., \& Van Loon, L. C. (1998). A novel signaling pathway controlling induced systemic resistance in Arabidopsis. The Plant Cell, 10, 1571-1580.

Raaijmakers, J. M., Leeman, M., Van Oorschot, M. P. M., Van der Sluis, I., Schippers, B., \& Bakker, P. A. H. M. (1995). Dose-response relationships in biological control of fusarium wilt of radish by Pseudomonas spp. Phytopathology, 85, 1075-1081.

Ryu, C.-M., Farag, M. A., Hu, C. H., Reddy, M. S., Wei, H. X., Paré, P. W., \& Kloepper, J. W. (2003). Bacterial volatiles promote growth in Arabidopsis. Proceedings of the $\mathrm{Na}$ tional Academy of Sciences of the United States of America, 100, 4927-4932.

Ryu, C.-M., Farag, M. A., Hu, C. H., Reddy, M. S., Kloepper, J. W., \& Paré, P. W. (2004). Bacterial volatiles induce systemic resistance in Arabidopsis. Plant Physiology, 134, 1017-1026.

Ryu, C.-M., Hu, C.-H., Locy, R. D., \& Kloepper, J. W. (2005). Study of mechanisms for plant growth promotion elicited 
by rhizobacteria in Arabidopsis thaliana. Plant and Soil, 268, 285-292.

Sanchez, L., Weidmann, S., Arnould, C., Bernard, A. R., Gianinazzi, S., \& Gianinazzi-Pearson, V. (2005). Pseudomonas fluorescens and Glomus mosseae trigger DMI3dependent activation of genes related to a signal transduction pathway in roots of Medicago trunculata. Plant Physiology, 139, 1065-1077.

Shuhegger, R., Ihring, A., Gantner, S., Bahnweg, G., Knappe, C., Vogg, G., Hutzler, P., Schmid, M., Van Breusegem, F., Eberl, L., Hartmann, A., \& Langebartels, C. (2006). Induction of systemic resistance in tomato by $N$-acyl-Lhomoserine lactone-producing rhizosphere bacteria. Plant, Cell and Environment, 29, 909-918.

Sticher, L., Mauch-Mani, B., \& Métraux, J.-P. (1997). Systemic acquired resistance. Annual Review of Phytopathology, 35, 235-270.

Tanimoto, E. (2005). Regulation of root growth by plant hormones: Roles for auxin and gibberellin. Critical Reviews in Plant Sciences, 24, 249-265.

Timmusk, S., \& Wagner, E. G. H. (1999). The plant-growthpromoting rhizobacterium Paenibacillus polymyxa induces changes in Arabidopsis thaliana gene expression: A possible connection between biotic and abiotic stress responses. Molecular Plant-Microbe Interactions, 12, 951-959.

Ton, J., Davison, S., Van Wees, S. C. M., Van Loon, L. C., \& Pieterse, C. M. J. (2001). The Arabidopsis ISR1 locus controlling rhizobacteria-mediated induced systemic resistance is involved in ethylene signaling. Plant Physiology, 125, 652-661.

Ton, J., Van Pelt, J. A., Van Loon, L. C., \& Pieterse, C. M. J. (2002). Differential effectiveness of salicylate-dependent and jasmonate/ethylene-dependent induced resistance in Arabidopsis. Molecular Plant-Microbe Interactions, 15, 27-34.

Van Loon, L. C. (2000). Systemic induced resistance. In A. J. Slusarenko, R. S. S. Fraser \& L. C. Van Loon (Eds.), Mechanisms of resistance to plant diseases (pp. 521-574). Dordrecht, The Netherlands: Kluwer Academic Publishers.

Van Loon, L. C., \& Bakker, P. A. H. M. (2003). Signalling in rhizobacteria-plant interactions. In H. De Kroon \& E. J. W. Visser (Eds.), Root ecology, (Ecological studies Vol. 168, pp. 297-330). Berlin, Heidelberg: Springer-Verlag.

Van Loon, L. C., \& Bakker, P. A. H. M. (2005). Induced systemic resistance as a mechanism of disease suppression by rhizobacteria. In Z. A. Siddiqui (Ed.), PGPR: Biocontrol and biofertilization (pp. 39-66). Dordrecht, The Netherlands: Springer Science.

Van Loon, L. C., \& Bakker, P. A. H. M. (2006). Root-associated bacteria inducing systemic resistance. In S. S. Gnanamanickam (Ed.), Plant-associated bacteria (pp. 269-316). Dordrecht, The Netherlands: Springer.

Van Loon, L. C., Bakker, P. A. H. M., \& Pieterse, C. M. J. (1998). Systemic resistance induced by rhizosphere bacteria. Annual Review of Phytopathology, 36, 453-483.

Van Luijk, A. (1938). Antagonism between various microorganisms and different species of the genus Pythium, parasitizing upon grasses and lucerne. Mededelingen van het Phytopathologisch Laboratorium "Willie Commelin Scholten"'- Baarn, 14, 43-83.
Van Peer, R., Niemann, G. J., \& Schippers, B. (1991). Induced resistance and phytoalexin accumulation in biological control of fusarium wilt of carnation by Pseudomonas sp. strain WCS417r. Phytopathology, 81, 728-734.

Van Wees, S. C. M., Luijendijk, M., Smoorenburg, I., Van Loon, L. C., \& Pieterse, C. M. J. (1999). Rhizobacteriamediated induced systemic resistance (ISR) in Arabidopsis is not associated with a direct effect on expression of known defense-related genes but stimulates the expression of the jasmonate-inducible gene Atvsp upon challenge. Plant Molecular Biology, 41, 537-549.

Verhagen, B. W. M., Glazebrook, J., Zhu, T., Chang, H. S., Van Loon, L. C., \& Pieterse, C. M. J. (2004). The transcriptome of rhizobacteria-induced systemic resistance in Arabidopsis. Molecular Plant-Microbe Interactions, 17, 895-908.

Vessey, J. K. (2003). Plant growth promoting rhizobacteria as biofertilizers. Plant and Soil, 255, 571-586.

Visker, M. H. P. W., Keizer, L. C. P., Budding, D. J., Van Loon, L. C., Colon, L. T., \& Struik, P. C. (2003). Leaf position prevails over plant age in reflecting resistance to late blight in potato. Phytopathology, 93, 666-674.

Wang, C., Knill, E., Glick, B. R., \& Défago, G. (2000). Effect of transferring 1-aminocyclopropane-1-carboxylic acid (ACC) deaminase genes into Pseudomonas fluorescens strain CHA0 and its gacA derivative CHA96 on their growth-promoting and disease-suppressive capacities. Canadian Journal of Microbiology, 46, 898-907.

Wang, Y., Ohara, Y., Nakayashiki, H., Tosa, Y., \& Mayama, S. (2005). Microarray analysis of the gene expression profile induced by the endophytic plant growth-promoting rhizobacteria, Pseudomonas fluorescens FPT9601-T5 in Arabidopsis. Molecular Plant-Microbe Interactions, 18, 385-396.

Wei, G., Kloepper, J. W., \& Tuzun, S. (1991). Induction of systemic resistance of cucumber to Colletotrichum orbiculare by select strains of plant growth-promoting rhizobacteria. Phytopathology, 81, 1508-1512.

Weller, D. M., Van Pelt, J. A., Mavrodi, D. V., Pieterse, C. M. J., Bakker, P. A. H. M., \& Van Loon, L. C. (2004). Induced systemic resistance (ISR) in Arabidopsis against Pseudomonas syringae pv. tomato by 2,4-diacetylphloroglucinol (DAPG)-producing Pseudomonas fluorescens. Phytopathology, 94, S108.

Whitehead, N. A., Barnard, A. M., Slater, H., Simpson, N. J., \& Salmond, G. P. (2001). Quorum-sensing in Gram-negative bacteria. FEMS Microbiology Reviews, 25, 365-404.

Zehnder, G., Kloepper, J., Yao, C. B., \& Wei, G. (1997). Induction of systemic resistance in cucumber against cucumber beetles (Coleoptera: Chrysomelidae) by plant growth-promoting rhizobacteria. Journal of Economic Entomology, 90, 391-396.

Zeidler, D., Zähringer, U, Gerber, I., Dubery, I., Hartung, T., Bors, W., Hutzler, P., \& Durner, J. (2004). Innate immunity in Arabidopsis thaliana: Lipopolysaccharides activate nitric oxide synthase (NOS) and induce defense genes. Proceedings of the National Academy of Sciences of the United States of America, 101, 15811-15816.

Zipfel, C., Robatzek, S., Navarro, L., Oakeley, E. J., Jones, J. D. G., Felix, G., \& Boller, T. (2004). Bacterial disease resistance in Arabidopsis through flagellin perception. Nature, 428, 764-767. 